Resumo

O presente estudo partiu do interesse em compreender as implicações da relação mãe-criança na obesidade infantil. A Organizaşão Mundial de Saúde revela a doença como um desafio aos programas de saúde. Considerando-se que a relação da criança com o alimento é mediada, em geral, pela mãe, propõe-se investigar, numa perspectiva psicanalitica, as implicações desta relação na obesidade infantil. Além da pesquisa bibliográfica, foi realizada a escuta de quatro mães de crianças obesas de 7 a 11 anos de idade. Conclui-se que a obesidade infantil pode ser considerada um sintoma da criança em resposta à posição subjetiva da mãe. Descritores: obesidade infantil; psicanálise; relação-mãecriança.

\section{IMPLICAÇÕES SUBJETIVAS DA RELAÇÃO MÃE- CRIANÇA NOS QUADROS DE OBESIDADE INFANTIL}

\author{
Fabiana Azeredo de Oliveira \\ Karla Patricia Holanda Martins
}

\section{Introdução}<smiles>c1ccccc1</smiles>

s levantamentos epidemiológicos realizados pela Organização Mundial de Saúde (OMS) revelam que a obesidade infantil vem se constituindo como uma doença recidivante e enigmática, considerada um desafio para os programas de saúde pú-

- Mestre em Psicologia pela Universidade de Fortaleza, membro do Laboratório de Estudos e Intervenções Psicanalíticas na Clínica e no Social (LEIPCS), associado ao Programa de Pós-graduação em Psicologia

- Professora-colaboradora do Programa de Pós-graduação em Psicologia pela Universidade de Fortaleza; Professora Adjunta da Universidade Federal do Ceará. 
blica em todo o mundo. As mudanças das condições nutricionais no Brasil, entre outros fatores, insere o país nesse panorama (Azevedo \& Spadotto, 2004; Friedman \& Alves, 2009). Mesmo existindo divergências em relação à sua etiologia na infância, as práticas de prevenção convergem para dois pontos de consonância: os hábitos alimentares considerados inadequados e o estilo de vida sedentário são os responsáveis diretos pelo estabelecimento do quadro (Oliveira \& Fisberg, 2003; Oliveira \& Cerqueira, 2003; Friedman \& Alves, 2009). Ainda nessa direção, as estratégias de prevenção da doença estão focadas na promoção do controle sobre a alimentação e o estilo de vida.

Todavia, a reflexão sobre a influência dos fatores socioculturais deve se estender à dimensão familiar. $\mathrm{O}$ alimento, considerado para além de seu valor nutricional, é um mediador das relações da criança com seus cuidadores primários, a mãe em particular. Desse modo, o presente artigo fará um recorte nesta perspectiva, discutindo as possíveis implicações da relação mãe-criança no estabelecimento da obesidade na infância.

$\mathrm{Na}$ direção dos estudos psicanalíticos, a obesidade será tomada como um sintoma, e portanto como uma via de representação de uma posição inconsciente. O modo como os sintomas se estabelecem na infância, a posição e implicação das mães, em particular, serão discutidos, a partir dos significados atribuídos por estas à obesidade dos filhos.

Inicialmente, parte-se dos estudos de Freud e Lacan. Os estudos freudianos sobre a constituição psíquica são privilegiados a partir dos desdobramentos lacanianos sobre o desejo do Outro como ancoragem fundamental da constituição do sujeito, para em seguida retomarmos o estudo de campo.

\section{Metodologla}

Com vistas à investigação do tema em questão, foi realizado um levantamento bibliográfico, onde foram definidos os pressupostos psicanalíticos como uma teoria de sustentação e interpretação dos dados obtidos em campo.

A pesquisa de campo foi realizada ao longo de quatro meses no Programa de Prevenção à Obesidade Infantil do Instituto de 
Promoção da Nutrição e do Desenvolvimento Humano (IPREDE/Fortaleza). Os atendimentos no programa não se limitavam somente às crianças, consistiam inclusive em um trabalho específico com as mães, através de grupos terapêuticos e de orientação às mães, e oficinas de culinária com a equipe de nutrição. Participamos como observadores dessas atividades institucionais, ao mesmo tempo em que os profissionais envolvidos no programa também foram escutados.

Após autorização do Conselho de Ética foi feito o agendamento das entrevistas com as mães. Com cada uma das mães foram realizadas três entrevistas de 50 minutos, com intervalo de tempo de, em média, quinze dias. O grupo de entrevistadas era composto por quatro mães de crianças de 7 a 11 anos de idade que frequentavam assiduamente o Programa. Foram incluídas nesta amostra mães de crianças que não apresentavam outras morbidades associadas à obesidade.

Para as autoras Costa e Poli (2006), na prática da entrevista alicerçada em pressupostos psicanalíticos, o objeto de pesquisa possui a característica paradoxal de ser também sujeito. O sujeito entrevistado é aquele que está assujeitado às leis que organizam a linguagem, portanto, ao inconsciente, "trazendo a marca de sua presença”" (Costa \& Poli, 2006, p. 15). Desse modo, a entrevista deve dar lugar ao inesperado, ao não sabido.

124 Estilos da Clínica, 2012, 17(1), 122-135 
Os dados colhidos nas entrevistas (semiestruturadas) foram analisados qualitativamente, buscando responder à problemática do presente estudo. Os resultados foram comparados com as informações relevantes oferecidas pelos teóricos pesquisados. Entende-se por análise qualitativa aquela na qual os dados serão interpretados de forma interrelacional, buscando identificar e relacionar as informações obtidas através do que foi verbalizado nas entrevistas (Minayo, 2006).

Como técnica para essa análise, foi utilizada a Análise de Discurso, no intuito de investigar nas produções dos sentidos os significados atribuídos à problemática em questão. Segundo Spink (1999, p. 42), "essa prática é social, dialógica, que implica a linguagem em uso ... e busca entender as práticas discursivas que atravessam o cotidiano como repertórios utilizados nessas produções".

Paralelamente às entrevistas, tivemos oportunidade de participar do grupo de psicoterapia que o programa oferecia às mães e assim pôde-se apreender os significados em relação à obesidade do(a) filho(a), diante do grupo. O encontro com essas mães também se deu na sala de espera que antecedia o atendimento semanal da dupla, onde foi observado o processo de separação com os filhos, quando simultaneamente eram destinadas às crianças atividades em sala, separadas das mães.

No presente recorte, retomam-se algumas falas relativas à angústia materna de modo a pensá-la em articulação com o sintoma da obesidade da criança.

\section{Angústia materna e formação do sintoma na criança}

Buscamos, no texto de Freud (1926/1980a), "Inibição, sintoma e angústia", algumas pontuações para questões que acreditamos serem cruciais na expressão de nossa temática. Quando Freud (1926/ 1980a, p. 137) diz "que não é possível achar que a angústia tenha qualquer outra função, afora a de ser um sinal para evitar uma situação de perigo", ele nos sinaliza que os estados de angústia podem decorrer, por exemplo, do medo da separação da mãe. Retoma a hipótese formulada no caso de fobia do "Pequeno Hans" onde ressalta que "a força motriz do recalque era o medo de castração" (1909/ 
1975, p. 31). Por esse caminho, acreditamos ser necessário refletir sobre um fio de continuidade entre a geração da angústia e o aparecimento do sintoma mãe/filho na obesidade infantil.

Em O seminário, livro 10: a angústia, Lacan (2005, p. 98) formula a angústia como "um afeto que não é sem objeto", inovando a concepção freudiana sobre o assunto. O que quer dizer nesse estatuto é que não há uma maneira de satisfação completa sem objeto. O objeto existe, embora não pareça, e só funciona "em correlação com a angústia".

O que Lacan faz, nessa ocasião, é interpretar a angústia como um afeto que se encontra inserido em uma série significante, e assim distingue-o da emoção. Freud (1926/1980a) conceituou "Inibição", "Sintoma"e "Angústia" como três eixos diferenciados, já Lacan (2005), a partir dos mesmos, propõe posições subjetivas. Os conceitos de "impedimento", "embaraço" e "comoção" (pp. 18-24) esclarecem que a dificuldade e o movimento em inibição e sintoma estariam em registros diferentes se comparados ao da angústia.

Como já foi dito, diferentemente da concepção freudiana sobre a angústia, Lacan propõe que esse afeto não se sustenta em um objeto, mas nos significantes do objeto. A castração para Freud é o objeto da angústia. Porém, para Lacan, a angústia emerge diante de um não saber fazer diante da falta do Outro. Se para
Freud, o sujeito se depara com "um ponto intransponível" (Lacan, 2005, p. 55), em Lacan esse ponto é a construção do significante da falta do Outro. Desse modo, o sujeito do inconsciente emerge desta indeterminação. Compreende-se, portanto, diante da temática em questão, que a angústia pode ter sido evocada a partir de um não saber que move o sujeito ao desejo. A obesidade como sintoma instala-se como uma saída para a solução de um conflito.

Lacan (2005) avança no campo da angústia elucidando o estatuto do objeto do desejo, ou seja, daquilo que instaura o desejo. Desse modo, propõe a angústia também como uma via de acesso a esse objeto. No campo do Outro, haveria algo que falta e o acesso ao desejo se faz por meio da angústia construída a partir do reconhecimento da falta. Ressalta que o Outro concerne a meu desejo na medida do que lhe falta. Afirma ainda: "é no nível do que lhe falta e do qual ele não sabe que sou implicado da maneira mais pregnante, porque, para mim não há outro desvio para descobrir o que me falta como objeto de meu desejo" (Lacan, p. 33).

Lacan (2005, p. 64), retomando as considerações de Freud (1926/ 1980a), propõe que a angústia não é apenas sinal à castração, mas angústia frente à possibilidade de não sustentação do desejo. É necessário fazer operar a alternância de presença e ausência para colocar em pauta a falta e o desejo. Pode-se assim supor 


\section{Artigo}

a possibilidade de uma via sintomática na relação mãe-criança, expressando-se na forma de uma tentativa da mãe de responder a todas as demandas do filho, através de uma presença em excesso, sem trégua. O que parece estar em jogo na formação do sintoma obesidade é a falta da falta a que Lacan faz referência como produtora de sofrimento e sintoma.

Diante dessa afirmação, passaremos a investigar a hipótese de que a obesidade pode se estabelecer como retorno do desejo inconsciente materno que se inscreve no corpo do filho. É do encontro entre real orgânico e simbólico que se abre uma fenda, onde a criança oferece seu corpo como uma via de articulação de dois registros. A condição de surgimento do sujeito do desejo se faz na dependência das relações entre necessidade e demanda, introduzidas pela falta, correlata da experiência de separação/castração. Desse modo, a passagem do infans para a criança é proporcionada pelo cruzamento de redes significantes entre o psíquico e o orgânico, a partir da posição de um outro - no caso, a mãe - capaz de encarnar a função do Outro.

Lacan (1969/2003a, p. 369), no texto "Notas sobre a criança", situa que: "o sintoma da criança acha-se em condição de responder ao que existe de somático na estrutura familiar". Portanto, o sintoma na criança define a verdade dos pais, acrescentando que quando se restringe na subjetividade da mãe, afunila o foco, reduzin- 
do a articulação na intervenção clínica. O sintoma somático na criança, como ainda diz Lacan (1938/2003), torna inacessível à mãe sua verdade, dando-lhe a garantia de permanecer desconhecida.

Seguindo essa perspectiva, Mannoni (1980a) retoma a ideia de que o sintoma da criança corresponde a uma certa "desordem familiar" (p. 70) e que o seu embate direto não se dá com a verdade dos pais, mas com a mentira. Dito de outro modo, é nas malhas do não dito que se esclarece a origem do sintoma. Diante da hipótese do recalque, a criança põe em cena a posição inconsciente dos pais, explica Manonni (1980); em outras palavras, o sintoma se apresenta na condição de um diálogo simbólico, na busca de um certo decifrar ao nível real.

A psicanalista Silvia Bleichmar (2002), em seu texto "Do discurso parental à especificidade sintomática na psicanálise de crianças" aponta, também a partir de sua experiência clínica, a dificuldade de apreender a significação das patologias na infância, quando as mesmas estão implicadas nos sintomas dos pais.

É no "discurso-desejo da mãe", como afirma a autora, que a psicanálise, em sua prática clínica, se precipita na busca de considerar o inconsciente como constituído. Sobre isso diz: "concebemos a realidade fundante do inconsciente infantil, como aquele que, estando em relação com o inconsciente parental, não é, no entanto, o sim- ples reflexo deste" (Bleichmar, 2002, p. 138).

As questões sobre o surgimento dos sintomas disparam como situações desencadeantes que são consideradas pela psicanálise como um reinvestimento de representações inconscientes. É necessário que emerja a articulação de um processo traumático anterior que, lançado em um dado momento, tem como via de escape o sintoma.

Diante disso, fazemos uma interlocução do sintoma com o texto "Os complexos familiares na formação do indivíduo", de Lacan (1938/2003). Para tanto, inicialmente esclarecemos que Lacan conceitua complexo como algo que reproduz a realidade familiar, apresentando-se diferenciado durante certa época do desenvolvimento psíquico. Os complexos possuem um papel organizador no desenvolvimento psíquico. O primeiro complexo a que Lacan (1938/2003) dá ênfase é o "complexo do desmame". Este consiste no modo de relação do sujeito com o alimento, carreando a forma primordial da imago materna. Porém, para a psicanálise, o desmame muitas vezes opera como um trauma psíquico, pois deixa no psiquismo um traço de uma relação biológica interrompida.

Lacan (1938/2003b) distingue o complexo do instinto, mas não nega que no complexo do desmame sua base material é biológica, condição que assegura ao sujeito sua dependência em relação ao grupo, ao social. 


\section{Artigo}

Com isso, explica que o processo do desmame é particularmente difícil, pois a mãe está presa "às profundezas do psiquismo", o que justifica as crianças muito apegadas à mãe, vinculadas numa "relação anacrônica" (p. 40).

O desmame remete à separação do nascimento, momento que "separa a criança da matriz" (Lacan, $1938 / 2003$, p. 40), e que nenhum cuidado materno posterior pode compensar. Assim, mais adiante, é preciso que novas relações se estabeleçam, condição necessária para que novos complexos interajam com o psiquismo. A morte, vivida pelo homem como "objeto de apetite" (Lacan, 1938/2003, p. 41) e que está presente em todos os níveis do psiquismo, revalida que no desmame o sujeito revive uma tendência psíquica de reencontrar a imago da mãe, e é essa tendência que é revelada nos traumas.

Para Queiroz (2005, pp. 207208), o desmame não é somente o instante de separação da criança ao seio da mãe, mas o "reflexo de divisão interna do sujeito e que em seu comportamento a criança manifesta sua atividade psíquica". Dito de outro modo, o desmame faz advir a queda do estatuto de um objeto: a criança supera sua angústia de separação, mas ao mesmo tempo encontra-se alienada na linguagem. É nessa divisão interna onde a criança se exclui do "conjunto da mãe, que agora é vista em sua totalidade". 
Mannoni (1980b), no seu texto "O sintoma ou a palavra", nos diz que é no sintoma que se manifesta o que se esclarece dizer. Dito de outro modo, a criança fala e todo seu discurso está no nível que o adulto pode suportar, e na ausência do direito de se significar verdadeiramente na linguagem, o sintoma "torna-se uma linguagem cifrada, de que a criança conserva o segredo” (p. 37).

\section{..."Ter pela metade é o mesmo que nada!"}

Através dos discursos das mães entrevistadas, percebe-se certa estranheza em relação aos (às) filhos (as), que, mesmo não comendo em excesso, engordam. É no istmo da duplicidade que Freud (1919) trabalha seu texto "O estranho", onde ressalta a dimensão paradoxal do que se apresenta, simultaneamente, como familiar e assustador.

Foi no contexto de sua elaboração sobre o narcisismo e a melancolia que Freud (1914/1976; 1915[1917]/1976) retoma o tema da identificação. Nessa ocasião, faz referência à identificação do eu com a imagem do objeto perdido; em outras palavras, a identificação resultante de uma reação à perda do objeto amado.

Lacan (s/d) retoma essa questão acrescentando que é a identificação ao traço unário que aponta uma falta. É nesse processo da identificação que a criança, na condição de um sujeito desejante, deve emergir de outro lugar. É necessário que a mãe se mostre desejante-faltante para que a separação (Lacan, 1960/1998) ocorra.

É interessante observar que essa estranheza está associada ao narcisismo da mãe, discutido por Freud (1914-15/1980b). Esta associação é revelada quando as mães ressaltam características dos filhos, semelhantes às delas, por uma via onde a identificação marca o laço entre ambos.

Acrescentamos a isso o que Crespin (2004) nos diz quando segue o pensamento de Lacan (1938/2003): é necessário ainda que a função paterna entre em cena como reguladora da onipotência primordial da mãe. Porém, o evento da separação/castração vem acrescido de uma angústia que é relativa à dupla mãe-filho. Nesse contexto, mãe e filho, extremamente identificados, angustiam-se com a possibilidade de uma separação. 


\section{Artigo}

Ainda sobre a separação, ressaltamos que é no desmame que sobrevém a angústia. Queiroz (2005, p. 191) afirma que a angústia "é consequência da cessão do objeto pela criança, quando esse objeto ainda é uma parte dela mesma, estando ainda pendurado em seu corpo". Dito de outro modo, a angústia nasce da emergência do laço por demais estreito com o outro (um nó) e não apenas de seu corte. Para algumas mães, mesmo que o peito - objeto do desmame - já não exista mais como objeto, o desmame ainda não foi feito. Os filhos que se mantém "grudados" em suas mães, ainda não conseguiram ser desmamados, como ilustra a seguinte fala: "ele é muito grudado em mim, só quer dormir se for comigo e comida só se eu fizer..."

Como foi dito anteriormente, para Lacan, a angústia irá decorrer de uma falta de sustentação à falta. Nesse fio de condução, pensamos na formação do sintoma da obesidade na infância, que se elabora a partir da tentativa de resolver um conflito. Portanto, a criança que responde aos desejos maternos com um sintoma em seu próprio corpo revela os votos inconscientes da mãe de partilhar suas angústias. Mannoni (1980b, p. 37) nos auxilia nesse instante quando esclarece que "na ausência do direito de se significar verdadeiramente na linguagem, é no sintoma que manifesta o que tem a dizer". Esse segredo decorre dos próprios sintomas da mãe, que atravessam o corpo do filho. É por esse viés que colocamos em cena 
a obesidade na infância como um sintoma/suporte dos fantasmas parentais.

Outras vezes, o sentido da obesidade se expressa no cansaço pela rotina com os cuidados com o filho. Quando fala dela mesma e seus desejos, diz: "tem que ter estudo completo, ter pela metade é o mesmo que nada!". As palavras "demais" e "muito" retornam várias vezes nos discursos sobre os filhos: "grande demais" e "gordo demais". Convém ressaltar que as mães entrevistadas também apresentam excesso de peso. Às vezes, partem de algumas questões sobre os impasses na aprendizagem escolar das crianças igualmente referenciadas em suas próprias dificuldades, "é lenta como eu", afirma uma das mães.

A demanda excessiva do alimento parecia corresponder a certa paralisação no ato de comer, além de um compromisso da dupla mãe-filho(a). Podemos pensar que esse fato faz jus à condição inativa do corpo obeso da criança. Alperovich (1956) citado por Kelner (2004) nos chama atenção para esse aspecto quando assinala a frase: "come y quedate quieto". Elabora que o obeso sedentário de hoje foi o filho imobilizado de ontem. Essa paralisação que se apresenta na dupla, diante do processar das falas, legitima sua incapacidade de movimentos, encerrado-a com o excesso de comida.

O sintoma emerge como uma via de escape e, simultaneamente, de submissão. $\mathrm{O}$ assujeitamento da criança ao capricho da mãe submete-a à posição de objeto de seu desejo, podendo perder-se como desejante. Portanto, é a partir do acesso à falta desse Outro materno que a criança pode encontrar seu significante, caso contrário acha-se situada na "insaciável voracidade" materna (Vorcaro, 2004, p. 114), elegendo o sintoma como via de escape para saída de uma posição de reconhecimento de seu desejo.

Pensamos que questões ainda podem ser desdobradas frente à complexidade da problemática. Todavia, no âmbito desse artigo, optou-se por discutir o desejo e a angústia materna e seus possíveis efeitos para o estabelecimento da obesidade infantil. O diálogo entre a psicanálise e as práticas de saúde possibilitou que as questões relativas ao ato do alimentar-se fossem pensadas e problematizadas a partir da complexa relação mãe-filho. Considera-se, portanto, que dimensão do desejo e suas implicações devem ser contrapostas a uma perspectiva marcada pelo discurso normativo e de regulação do excesso do "alimento", tão presente nos programas de tratamento e prevenção do quadro. 
SUBJECTIVE IMPLICATIONS OF THE RELATIONSHIP MOTHER-CHILD IN THE PRESENTMENT OF CHILDHOOD OBESITY

\section{Abstract}

The present study arouse from an interest to understand the mother-child relationship in childhood obesity. The World Health Organization (WHO) reveals that the disease offers big challenges to the bealth programs. Considering that the child's relation towards food is usually mediated by the mother, we intend to investigate, under a psychoanalytic perspective, the implications of such relationship in childhood obesity. In addition to the bibliographic research, we also listened to four mothers of obese children between 7 and 11 years old. We managed to conclude that childhood obesity can be considered a child's symptom in response to the subjective position of the mother.

Index terms: childhood obesity, psychoanalysis, mother-child relationship.

CONSECUENCIAS SUBJETIVAS DE LA RELACIÓN MADRE-HIJO EN LA OBESIDAD INFANTIL

\section{RESUMEN}

Elpresente estudio empezó del interés en comprender las consecuencias de la relación madre-hijo en la obesidad infantil. La Organización Mundial de la Salud muestra que la enfermedad se está convirtiendo en un reto para los programas de salud. Llevando en consideración que la relación del niño con los alientos es tomada en primer plano, en lo general la madre, se propone investigar, desde una perspectiva psicoanalitica, las consecuencias de esta relación. Además de la literatura, fue entrevistado un grupo compuesto por cuatro madres de niños obesos de 7 a 11 años. Se concluye que la obesidad infantil puede considerarse como un sintoma del niño en respuesta a la posición subjetiva de la madre.

Palabras clave: obesidad infantil; psicoanálisis; relaciones-madre-niño. 


\section{REFERÊNCIAS}

Azevedo, M. A. S. B., \& Spadotto, C. (2004). Estudo psicológico da obesidade: dois casos clínicos. Temas de Psicologia, 12(2), 127-144.

Bleichmar, S. (2002). Do discurso parental à especificidade sintomática na psicanálise de crianças. In A. M. S. Rosenberg (Org.). O lugar dos pais na psicanálise de crianças (pp. 120-155). São Paulo: Escuta.

Costa, A., \& Poli, M. C. (2006, dezembro). Alguns fundamentos da entrevista em psicanálise. Pulsional Revista de Psicanálise, 188, 14-21.

Crespin, G. (2004). A clínica precoce: o nascimento do bumano. São Paulo: Casa do Psicólogo.

Freud, S. (1980a). Inibições, sintomas e ansiedade. In S. Freud, Edição standard brasileira das obras psicológicas completas de Sigmund Freud (J. Salomão trad., Vol. 20, pp. 93-200). Rio de Janeiro: Imago. (Trabalho original publicado em 1926)

Freud S. (1980b). Sobre o narcisismo: uma introdução. In S. Freud, Edição standard brasileira das obras psicológicas completas de Sigmund Freud (J. Salomão trad., Vol. 14, pp. 83-119). Rio de Janeiro: Imago. (Trabalho original publicado em 1914-15)

Freud, S. (1975). Duas histórias clínicas: o pequeno Hans e o homem dos ratos. In S. Freud, Edição standard brasileira das obras psicológicas completas de Sigmund Freud (J. Salomão trad., Vol. 10, pp. 15-157). Rio de Janeiro: Imago. (Trabalho original publicado em 1909)

Freud, S. (1976). Luto e melancolia. In S. Freud, Edição standard brasileira das obras psicológicas completas de Sigmund Frend (J. Salomão trad., Vol. 14, pp. 271-292). Rio de Janeiro: Imago. (Trabalho original publicado em 1917)

Freud, S. (1980c). O estranho. In S. Freud, Edição standard brasileira das obras psicológicas completas de Sigmund Freud (J. Salomão trad., Vol. 17, pp. 273-327). Rio de Janeiro: Imago. (Trabalho original publicado em 1919)

Friedman, R., \& Alves, B. S. (2009). Obesidade infantil. In F. Bandeira (Org.), Endocrinologia e diabetes (pp. 663-673). Rio de Janeiro: Medbook.

Kelner, G. (2004). Transtornos alimentares: Um enfoque psicanalítico. Estud. Psicanal, 27, 33-44.

Lacan, J. (2003a). Notas sobre a criança. In J. Lacan, Outros escritos (pp. 369-370). Rio de Janeiro: Jorge Zahar. (Trabalho original publicado em 1969)

Lacan, J. (2003b). Os complexos familiares na formação do indivíduo - ensaio de análise de uma função em psicologia. In J. Lacan, Outros escritos (pp. 23-90). Rio de Janeiro: Jorge Zahar. (Trabalho original publicado em 1938)

Lacan, J. (2005). O seminário, livro 10: a angústia, 1962-1963. Rio de Janeiro: Jorge Zahar.

Lacan, J. (1998). Posição do inconsciente no Congresso de Bonneval. In J. Lacan, Escritos (pp. 843-864). Rio de Janeiro: Jorge Zahar. (Trabalho original publicado em 1960)

Lacan, J. (s/d). A identificação. Seminário 9, 1961-1962. Inédito.

Mannoni, M. (1980a). A primeira entrevista em psicanálise. Rio de Janeiro: Campus.

Mannoni, M. (1980b). O sintoma ou a palavra. In M. Mannoni. A crianca, sua "doença" e os outros (pp. 29-66). Rio de Janeiro: Jorge Zahar. 
Minayo, M. C. S. (2006). O desafio do conbecimento: pesquisa qualitativa em saúde. São Paulo: Editora Hucitec/Rio de Janeiro: Abrasco.

Oliveira, A. M. A. \& Cerqueira, E. M. M. (2003, Abril). Sobrepeso e obesidade infantil: influência de fatores biológicos e ambientais em Feira de Santana, BA. Arq. Bras. Endocrinologia Metabólica, 47(2), 144150.

Oliveira, C. L. \& Fisberg, A. M. (2003). Obesidade na infância e adolescência - uma verdadeira epidemia. Arq. Bras. Endocrinologia Metabólica, 1(3), 72-84.

Organização Mundial de Saúde. Obesidade infantil e desnutrição OMS. Recuperado em 12 dez. 2009: http: //www. obesidadeinfantil. org/artigos-obesidade-infantil/desnutri cao-oms-organizacao-mundial-saude.php

Queiroz, T. C. N. (2005). Do desmame ao sujeito. São Paulo: Casa do Psicólogo.

Spink, M. J. P. (1999). Práticas discursivas e produção de sentidos no cotidiano: aproximações teórico-metodológicas. São Paulo: Cortez.

Vorcaro, A. M. R. A criança na clínica psicanalítica. Rio de Janeiro: Companhia de Freud, 2004.

fabianazeredo@hotmail.com kphm@uol.com.br

Recebido em agosto/ 2001. Aceito em setembro/ 2011. 